PANCREAS

\title{
Specific interaction of tissue-type plasminogen activator ( $t$-PA) with annexin II on the membrane of pancreatic cancer cells activates plasminogen and promotes invasion in vitro
}

\author{
V M Díaz, M Hurtado, T M Thomson, J Reventós, R Paciucci
}

Gut 2004;53:993-1000. doi: 10.1136/gut.2003.026831

See end of article for authors' affiliations

\section{Correspondence to:} Dr R Paciucci, Unitat de Recerca Biomèdica, URB pl 14 Hospital MaternoInfantil Vall d'Hebrón, Pg Vall d'Hebrón, 119-129, 08035 Barcelona, Spain rpaciucci@vhebron.net

Accepted for publication 20 January 2004

\begin{abstract}
Background: Overexpression of tissue plasminogen activator ( $t-P A)$ in pancreatic cancer cells promotes invasion and proliferation in vitro and tumour growth and angiogenesis in vivo.

Aims: To understand the mechanisms by which t-PA favours cancer progression, we analysed the surface membrane proteins responsible for binding specifically t-PA and studied the contribution of this interaction to the t-PA promoted invasion of pancreatic cancer cells.

Methods: The ability of t-PA to activate plasmin and a fluorogenic plasmin substrate was used to analyse the nature of the binding of active t-PA to cell surfaces. Specific binding was determined in two pancreatic cancer cell lines (SK-PC-1 and PANC-1), and complex formation analysed by co-immunoprecipitation experiments and co-immunolocalisation in tumours. The functional role of the interaction was studied in Matrigel invasion assays.

Results: $t-P A$ bound to PANC-1 and SK-PC- 1 cells in a specific and saturable manner while maintaining its activity. This binding was competitively inhibited by specific peptides interfering with the interaction of t-PA with annexin II. The t-PA/annexin II interaction on pancreatic cancer cells was also supported by coimmunoprecipitation assays using anti-t-PA antibodies and, reciprocally, with antiannexin II antibodies. In addition, confocal microscopy showed t-PA and annexin II colocalisation in tumour tissues. Finally, disruption of the t-PA/annexin II interaction by a specific hexapeptide significantly decreased the invasive capacity of SK-PC-1 cells in vitro.

Conclusion: t-PA specifically binds to annexin II on the extracellular membrane of pancreatic cancer cells where it activates local plasmin production and tumour cell invasion. These findings may be clinically relevant for future therapeutic strategies based on specific drugs that counteract the activity of t-PA or its receptor annexin II, or their interaction at the surface level.
\end{abstract}

T ssue-type and urokinase plasminogen activators (t-PA and $\mathrm{u}-\mathrm{PA}$, respectively) are serine proteases that catalyse the activation of plasminogen in vivo. ${ }^{1}$ The activity of plasmin is critical in a number of physiological processes, including extracellular proteolysis, cell migration, tissue remodelling, and angiogenesis. ${ }^{23}$ Plasmin activity is also required for tumour progression, and the role of $\mathrm{u}-\mathrm{PA}$ in activating plasminogen is well documented. ${ }^{45}$ The activity of t-PA correlates with a poor prognosis in several cancers, including melanomas, ${ }^{6-8}$ neuroblastomas, ${ }^{9}{ }^{10}$ acute non-lymphocytic leukaemia, ${ }^{11}$ and cancer of the exocrine pancreas where its overexpression promotes growth and angiogenesis in vivo. ${ }^{12-15}$

Plasminogen is readily activated by t-PA and u-PA when both are bound to cell surfaces. ${ }^{16}$ Plasmin generated at these sites, protected from the activity of inhibitors such as $\alpha_{2}$-antiplasmin and $\alpha_{2}$-macroglobulin, ${ }^{17}$ is responsible for most of the proteolytic activity generated at membrane sites. Several proteins may function as binding sites for plasminogen or as co-binding sites for plasminogen and t-PA. ${ }^{18-21}$ Annexin II, a cytosolic phospholipid and $\mathrm{Ca}^{2+}$ binding protein, is a co-receptor for t-PA and plasminogen in endothelial cells ${ }^{22}$ that can form heterotetrameric complexes on the surface of HUVEC cells with the annexin II light chain (called S100Al0 or pll) and this stimulates generation of t-PA dependent plasmin. ${ }^{17}{ }^{23}$ The annexin II/t-PA interaction is required for activation of microglia, ${ }^{24}$ and for plasmin generation in nerve growth factor activated neuritogenesis. ${ }^{25}$ Amphoterin, a heparin binding protein, binds t-PA and promotes neurite outgrowth in neuroblastoma cells. ${ }^{26}$
Cytokeratin 18 and 8 bind t-PA in hepatocellular and breast carcinoma cells. ${ }^{27}$ In addition, interactions of t-PA with surface membrane proteins dependent on its kringle domains or the catalytic site have been described ${ }^{28-31}$ Very recently, the transmembrane protein CKAP4 has been identified as a specific t-PA binding protein on the surface of vascular smooth muscle cells. ${ }^{32}$

We have previously shown that overexpression of t-PA in pancreatic cancer cells potentiates their invasive capacity and induces proliferation and faster tumour growth in vivo. ${ }^{13-15}$ The mechanisms by which t-PA promotes its different functions in pancreatic cancer cells have not been investigated. In the present work, we focused on the molecules that specifically bind active t-PA on the surface of cells and participate in invasion.

\section{EXPERIMENTAL PROCEDURES}

Cell culture and reagents

Cell lines were obtained from American Type Culture Collection (Rockville, Maryland, USA) and maintained in Dulbecco's modified Eagle's medium (DMEM) (Gibco-BRL, Gaithesburg, New York, USA) supplemented with 10\% heat

Abbreviations: t-PA, tissue-type plasminogen activator; rt-PA, recombinant t-PA; DFP-t-PA, t-PA inactivated by DFP; DFP, diisopropyl fluorophosphate; PAl-1, plasminogen activator inhibitor 1; u-PA, urokinase-type plasminogen activator; AMC, 7-amido-4methylcoumarin; DMEM, Dulbecco's modified Eagle's medium; FBS fetal bovine serum; PBS, phosphate buffered saline; BSA, bovine serum albumin; rfu, relative fluorescence units 
inactivated fetal bovine serum (FBS; Gibco-BRL) at $37^{\circ} \mathrm{C}$ and $5 \% \mathrm{CO}_{2} \cdot{ }^{15}$ Goat antibodies recognising t-PA were from American Diagnostica (Greenwich, Connecticut, USA); antibodies to annexin I and annexin II were from Transduction Laboratories (Lexington, Kentucky, USA); anti-ERK 1,2, from Upstate Biotechnology (Lake Placid, New York, USA); antimouse FITC biotin labelled rabbit antigoat IgG and mouse IgGs from Dako (Glostrup, Denmark); antigoat TRITC from Pierce (Rockford, Illinois, USA); diisopropyl fluorophosphate (DFP), goat IgGs, streptavidin-agarose, and protein G agarose beads from Sigma (St Louis, Missouri, USA); and plasminogen and recombinant t-PA (rt-PA, Actilyse) from Boehringer Mannheim (Barcelona, Spain). Peptides LCKLSL and LGKLSL were synthesised at the Serveis Científico Tècnics, Universitat Pompeu Fabra (Barcelona, Spain).

\section{Functional cell membrane binding assay for t-PA}

Interaction of t-PA with the surface of pancreatic tumour cells was studied by analysing the plasminogen activating capacity of bound recombinant t-PA (rt-PA). ${ }^{30}{ }^{31}$ Briefly, cells were seeded $\left(7 \times 10^{4}\right.$ cells/well $)$ in 24 well plates and grew to confluence. Endogenous plasminogen activators were removed from cell surfaces with acid glycine buffer $(0.05 \mathrm{M}$ glycine $(\mathrm{pH} \mathrm{3}), 0.1 \mathrm{M} \mathrm{NaCl})$ for three minutes and neutralised with $0.5 \mathrm{M}$ HEPES $(\mathrm{pH} 7.5)$ and $0.1 \mathrm{M} \mathrm{NaCl}$. Cells were incubated with different concentrations of rt-PA for 20 minutes at $37^{\circ} \mathrm{C}$ in phosphate buffered saline (PBS) containing $2 \%$ bovine serum albumin (BSA, binding buffer). After washing with binding buffer, bound t-PA was determined by incubating cells directly in $0.05 \mathrm{M}$ Tris $\mathrm{HCl}$, $0.1 \mathrm{M} \mathrm{NaCl}, \mathrm{pH} 7.4$, with plasminogen $(0.2 \mu \mathrm{M})$ and H-DVal-Leu-Lys-7-amido-4-methylcoumarin (AMC $0.2 \mathrm{mM}$ ) (Bachem, Budendorf, Switzerland), a plasmin specific fluorogenic peptide substrate. ${ }^{30}$

To determine the linearity of plasminogen activation, fluorescence levels (relative fluorescence units (rfu)) were measured at different times after incubation with substrates at excitation and emission wavelengths of $380 \mathrm{~nm}$ and $480 \mathrm{~nm}$, respectively, using a Fluoroskan Reader (Labsystems, Helsinki, Finland).

\section{Equilibrium, saturation, and competition binding assays}

To determine the time needed to reach equilibrium, PANC-1 cells were incubated with rt-PA $(15 \mathrm{nM})$ at $37^{\circ} \mathrm{C}$ for different time periods, cells were washed, and plasminogen activation was determined. For equilibrium saturation binding assays, PANC-1 cells were incubated with rt-PA at different concentrations (0-500 $\mathrm{nM})$ for 20 minutes, and plasmin generation was determined. To convert rfu data to t-PA protein concentration, a standard t-PA in a fibrin coupled enzymatic assay was used (Desafib-X, Biopool, Sweden). ${ }^{33}$ Competitive binding assays were performed with peptides blocking the interaction of t-PA with annexin II (LCKLSL) or control peptides (LGKLSL) used at $0.1-10 \mathrm{mM}^{34}$ To remove annexin II from cell surfaces, cells were rinsed with PBSEDTA $(0.5 \mathrm{mM})$ and incubated with PBS-EDTA plus EGTA (10-50 mM) for 20 minutes. ${ }^{35}$ Supernatants from treated cells were concentrated by centrifugation with Ultrafree-4 filters Biomax-10K (Millipore, Bedford, Massachusetts, USA). To assay cells in suspension for t-PA binding, cells were trypsinised, washed, and resuspended in fresh medium for one hour at $37^{\circ} \mathrm{C}$ in polypropylene tubes before proceeding to the binding reaction.

For SK-PC- 1 cells (overexpressing t-PA), to avoid contamination with the endogenous protein, bound rt-PA was rapidly eluted from cells in acid buffer, neutralised, and its activity measured using a fibrin coupled enzymatic assay.

\section{Analyses of binding data}

Equilibrium and saturation binding data were analysed by non-linear regression algorithms using Sigma Plot software (SPSS, Chicago, Illinois, USA). For saturation binding analyses, data were fit to a one or two binding site model.

\section{Western blotting and immunoprecipitation}

Western blotting was performed as described previously. ${ }^{15}$ For immunoprecipitation, subconfluent SK-PC-1 cells were lysed in buffer I (20 mM Tris $\mathrm{HCl}, \mathrm{pH} 6.8,3 \mathrm{mM} \mathrm{MgCl}_{2}$, $50 \mathrm{mM} \mathrm{NaCl}, 300 \mathrm{mM}$ sucrose, $1 \%$ Triton X-100 (v/v)) containing $1 \mathrm{mM}$ phenylmethylsulphonyl fluoride and $2 \mu \mathrm{g} / \mathrm{ml}$ each of aprotinin, leupeptin, and pepstatin. ${ }^{36}$ After centrifugation ( $13000 \mathrm{~g}$ ) the pellet containing annexin II was dissolved in buffer II $(50 \mathrm{mM}$ Tris $\mathrm{HCl}, 150 \mathrm{mM} \mathrm{NaCl}, 1 \%$ NP-40, $10 \mathrm{mM}$ EGTA). Proteins $(400 \mu \mathrm{g})$ from the supernatant and pelletted fractions were used for immunoprecipitation with antiannexin II, anti-t-PA, antiannexin-I antibodies, or goat IgGs, and recovered by protein $G$ sepharose beads or antigoat biotinylated IgG and streptavidin agarose beads. After washing with buffer II without EGTA, beads were resuspended in Laemmli buffer, and immunoprecipitated proteins were identified by western blotting.
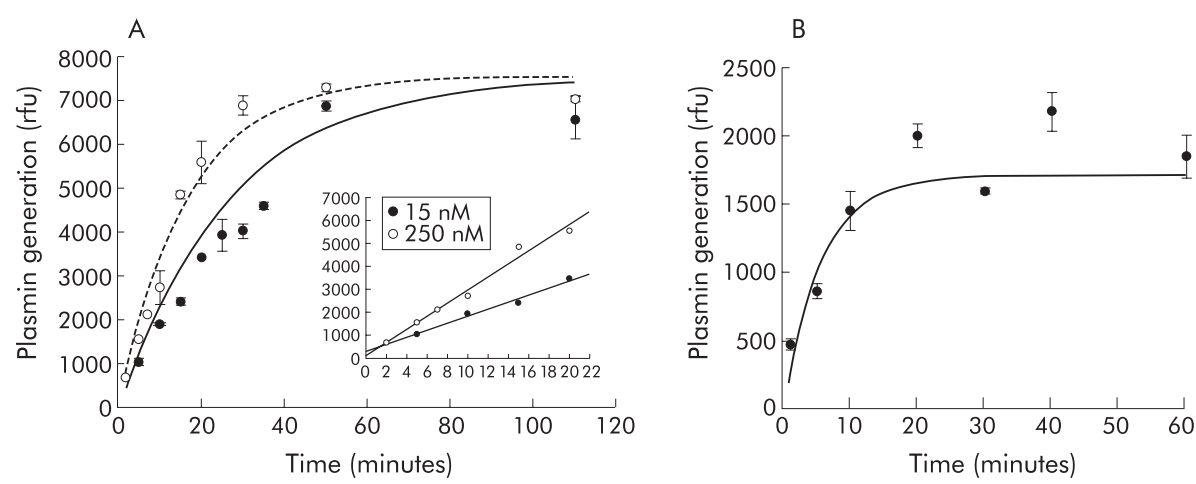

Figure 1 Binding of tissue-type plasminogen activator (t-PA) to the surface of pancreatic cancer cells determined by a functional assay. (A) t-PA catalysed plasminogen activation on PANC-1 cells. Cells were grown until confluence and preincubated with $15 \mathrm{nM}$ or $250 \mathrm{nM}$ of recombinant t-PA over 20 minutes. Cells were then washed to remove unbound t-PA, and plasmin generation was determined at different times after addition of plasminogen $(0.2 \mu \mathrm{M})$ and H-D-Val-Leu-Lys-7-amido-4-methylcoumarin (AMC $0.2 \mathrm{mM})$, as described in experimental procedures. Data shown for relative fluorescence units ( $\mathrm{rfu}$ ) represent generation of active plasmin by active t-PA. Inset shows the linearity of plasmin generation during the first 20 minutes of the reaction. (B) Time course of binding of t-PA to PANC-1 cells. Cells were preincubated with $15 \mathrm{nM}$ t-PA at $37^{\circ} \mathrm{C}$ for the times indicated and plasmin generation was determined after 15 minutes. Equilibrium binding was reached at 20 minutes. Data are mean (SEM) of values from two experiments performed in triplicate. 

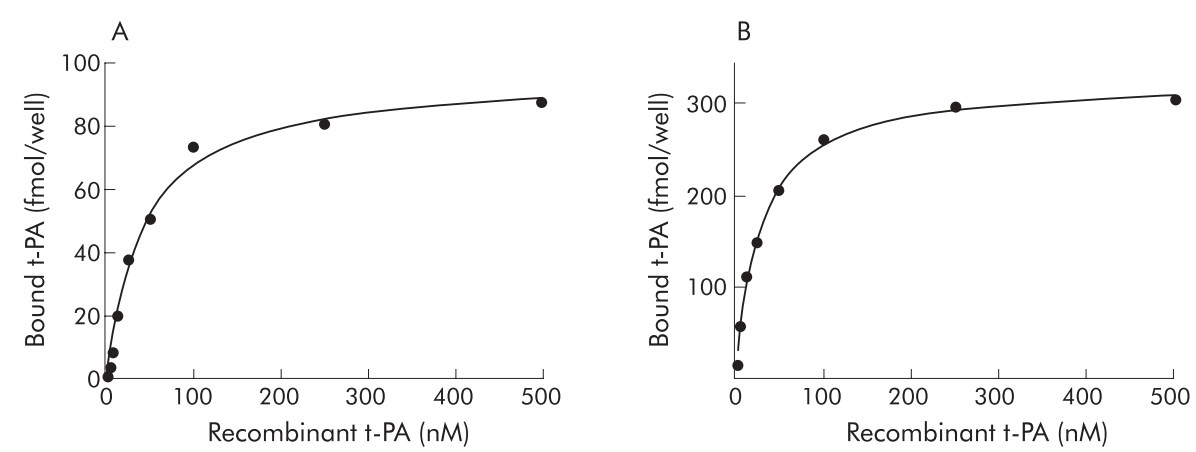

Figure 2 Binding of tissue-type plasminogen activator (t-PA) to PANC-1 and SK-PC-1 cancer cells. PANC-1 (A) and SK-PC-1 (B) cells were grown until confluence and incubated with increasing concentrations of recombinant t-PA for 20 minutes. Bound t-PA was determined 15 minutes after addition of substrate. One representative experiment of four performed in triplicate is indicated. Shown is the best fit of binding models to the data. The binding constants, as revealed by non-linear regression analyses of the data, are indicated in the text.

\section{Immunohistochemical staining and confocal microscopy}

Sections $(5 \mu \mathrm{m})$ from paraffin embedded tissues were treated with heat in citrate buffer for antigen retrieval. Sections were incubated with antiannexin II and anti-t-PA antibodies, rinsed, and incubated with purified FITC conjugated antimouse IgG and TRITC conjugated antigoat IgG. After rinsing, sections were mounted with Immuno-Fluore Mounting Medium (ICN, Costa Mesa, California, USA). Fluorescence was visualised on an inverted fluorescence microscope DM IRBE (Leica, Wetzlar, Germany) and captured in a TCS-NT argon/kripton confocal laser microscope (Leica). Control sections were incubated with matched mouse or goat IgG and were found to be negative. Incubations with rabbit secondary antibodies were also unreactive.

\section{In vitro invasion assays}

The invasive potential of cultured tumour cells was tested using Matrigel coated Transwell filters (Costar, Cambridge, Massachusetts, USA), as previously described..$^{15}$ Briefly, $1 \times 10^{5}$ cells were resuspended in DMEM supplemented with $0.1 \%$ BSA and plated on the Matrigel coated filters in the upper chamber, and medium containing $10 \%$ FBS was placed in the bottom chamber. Plates were incubated at $37^{\circ} \mathrm{C}$ for 24 , 48 , or 72 hours, after which cells that reached the bottom surface of the filters were visualised by staining with crystal violet. Peptides LCKLSL and LGKLSL were tested on cell invasion by mixing them with cells before seeding. Quantitative analyses were performed by counting stained cells on the filters in 10 independent fields/Transwell. Invasion abilities of cells were assigned as follows: highly invasive $(+++), \geqslant 100$ cells/field at 24 hours; moderately invasive $(++), \geqslant 100$ cells/field at 48 hours; and poorly invasive (+), 50-100 cells/field at 72 hours. Quantitative analyses of stained filters were also obtained by elution in $10 \%$ acetic acid and measuring absorbance at $595 \mathrm{~nm}$.

\section{Statistics}

Results are expressed as mean (SEM) and the Student's $t$ test was used for statistical analysis. A p value of $<0.05$ was considered statistically significant in all cases.

\section{RESULTS}

t-PA binds specifically and saturably to the surface of pancreatic cancer cells

Because pancreatic cancer cells express plasminogen activator inhibitor 1 (PAI-1) (Díaz and colleagues ${ }^{15}$ and data not shown), the physiological inhibitor of t-PA that binds with high affinity and inactivates t-PA, and the t-PA/PAI- 1 complex can bind to cell surface receptors, ${ }^{16}$ t-PA binding
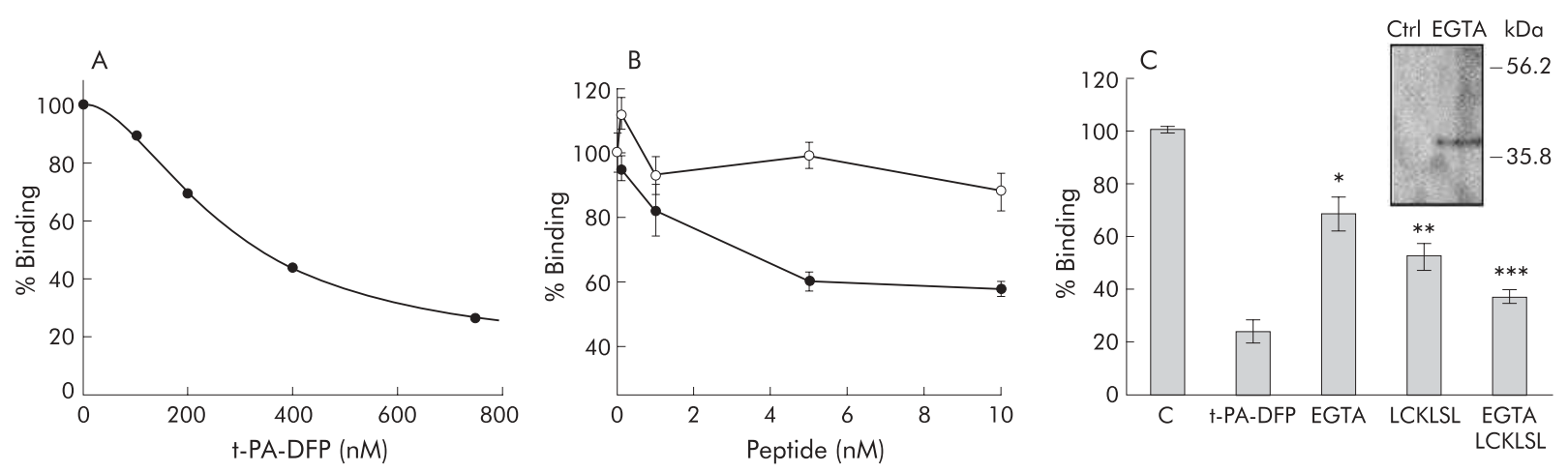

Figure 3 Involvement of annexin II in the binding of tissue-type plasminogen activator ( $t-P A)$ to pancreatic cancer cells. Experiments were performed with confluent PANC-1 monolayers. (A) Specificity of t-PA binding was tested using as a competitor of recombinant t-PA (rt-PA $10 \mathrm{nM}$ ) t-PA inactivated with diisopropyl fluorophosphate (DFP) at increasing concentrations. (B) Specific contribution of annexin II to binding of t-PA to the surface of PANC-1 cells was studied by disrupting the interaction with a blocking peptide (LCKLSL, filled symbols) or a control peptide (LGKLSL, open symbols). Data are mean (SEM) $(n=3)$. Inhibition of t-PA binding by LCKLSL was statistically significant ( $p=0.007$ compared with rt-PA only; $p=0.009$ compared with control peptide). (C) Annexin II was released from the cell surface by treatment with EGTA $(50 \mathrm{mM})$ prior to incubation with rt-PA with or without addition of peptide LCKLSL $(5 \mathrm{mM})$. Data are expressed as the percentage of binding of control samples without competitor and represent the mean (SEM) of triplicate samples from a single experiment. Three experiments were performed with very similar results. Inset shows a western blot performed with supernatants concentrated from control cells and EGTA treated cells blotted with antiannexin Il antibody. Statistical significance was determined by the Student's $t$ test: ${ }^{*} p=0.009,{ }^{* *} p=0.0004,{ }^{* * *} p=0.0001$. 


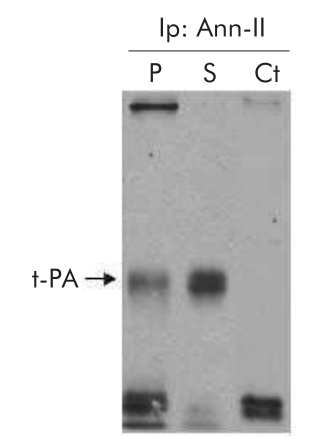

S

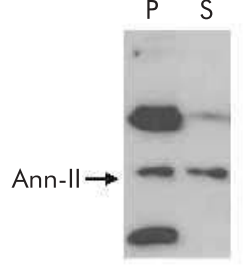

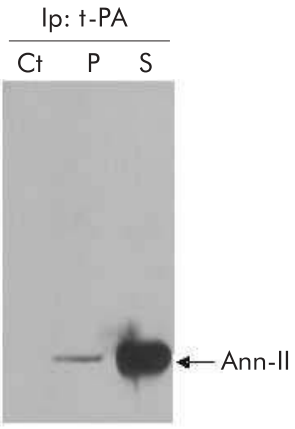

P S

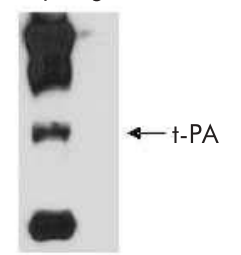

Figure 4 Co-immunoprecipitation of tissue-type plasminogen activator (t-PA) and annexin II. SK-PC-1 cells were maintained in complete medium until $70 \%$ confluence and processed as described in experimental procedures. Left panel: top, cell lysates were subjected to immunoprecipitation with an antibody to annexin II (lane P represents the pelletted fraction and lane $S$ the supernatant or non-immunoprecipitated fraction) or with isotype matching antiannexin I antibody as a control (lane Ct). The electrophoresed proteins were analysed by immunoblotting with anti-t-PA antibody; bottom, the efficacy of the antibody in immunoprecipitating annexin II was checked by blotting the pellet and supernatant fractions with antiannexin II antibody. Right panel: top, cell lysates were subjected to immunoprecipitation with a control goat serum (lane $\mathrm{Ct}$ ) or with anti-t-PA antibody (lane $\mathrm{P}$ represents the pelletted fraction and lane $S$ the supernatant or non-immunoprecipitated fraction) and proteins were analysed by immunoblotting with a mouse antiannexin II antibody; bottom, the efficacy of the antibody in immunoprecipitating t-PA was checked by blotting the pellet and supernatant fractions with anti-t-PA antibody. sites other than PAI-1 can be analysed by evaluating the fraction of active enzyme bound to the cell surfaces. ${ }^{30}$ To analyse putative receptors for t-PA that maintain the protease proteolytically active in pancreatic cancer cells, we used rt-PA and measured the activity of the bound protease by its ability to activate plasmin and a fluorogenic plasmin substrate. Firstly, we determined the linearity of plasmin generation by incubating PANC-1 cells with rt-PA (15 and $250 \mathrm{nM}$ ) over 20 minutes and, after washing out the unbound ligand, measuring hydrolysis of the AMC substrate at different times. As shown in fig $1 \mathrm{~A}$, generation of proteolysed AMC substrate is linear up to 30 minutes for t-PA at $15 \mathrm{nM}(\mathrm{r}=0,990)$. When t-PA is used at $250 \mathrm{nM}$, plasmin generation is linear up to 20 minutes $(r=0.983)$. Therefore, all subsequent determinations of bound t-PA activity were performed after 15 minutes of incubation with substrate.

Next, we determined the time for t-PA binding to reach equilibrium. As shown in fig $1 \mathrm{~B}$, binding of t-PA to PANC-1 cells at $37^{\circ} \mathrm{C}$ was time dependent and reached equilibrium after 20 minutes. Using non-linear regression analyses, the data depicted in fig $1 \mathrm{~B}$ fit to a monoexponential curve, suggesting a reversible bimolecular interaction.

We then determined the saturability of t-PA binding by incubating PANC-1 cells with increasing concentrations of rt-PA. As shown in fig 2A, cells demonstrated dose related and saturable binding of t-PA that reached a plateau at input doses of $100 \mathrm{nM}$. Non-linear regression analyses of these data showed that the best fit was to a one site binding model, with a $\mathrm{K}_{\mathrm{D}}$ of $42 \mathrm{nM}$. In parallel experiments, binding of t-PA to SK-PC-1 cells gave very similar results $\left(K_{D} 23.5 \mathrm{nM}\right.$; fig $2 \mathrm{~B})$. These values are very similar to previously reported binding affinity values to purified annexin II $\left(\mathrm{K}_{\mathrm{D}} 25 \mathrm{nM}^{22}\right)$, to 293 cells transfected with annexin II cDNA $\left(\mathrm{K}_{\mathrm{D}} 48 \mathrm{nM}^{37}\right)$, or to an unidentified receptor molecule on vascular smooth muscle cells $\left(\mathrm{K}_{\mathrm{D}} 25 \mathrm{nM}^{30}\right)$. The specificity of this binding was demonstrated by gradual inhibition of bound t-PA in cells treated with increasing concentrations of DFP inactivated

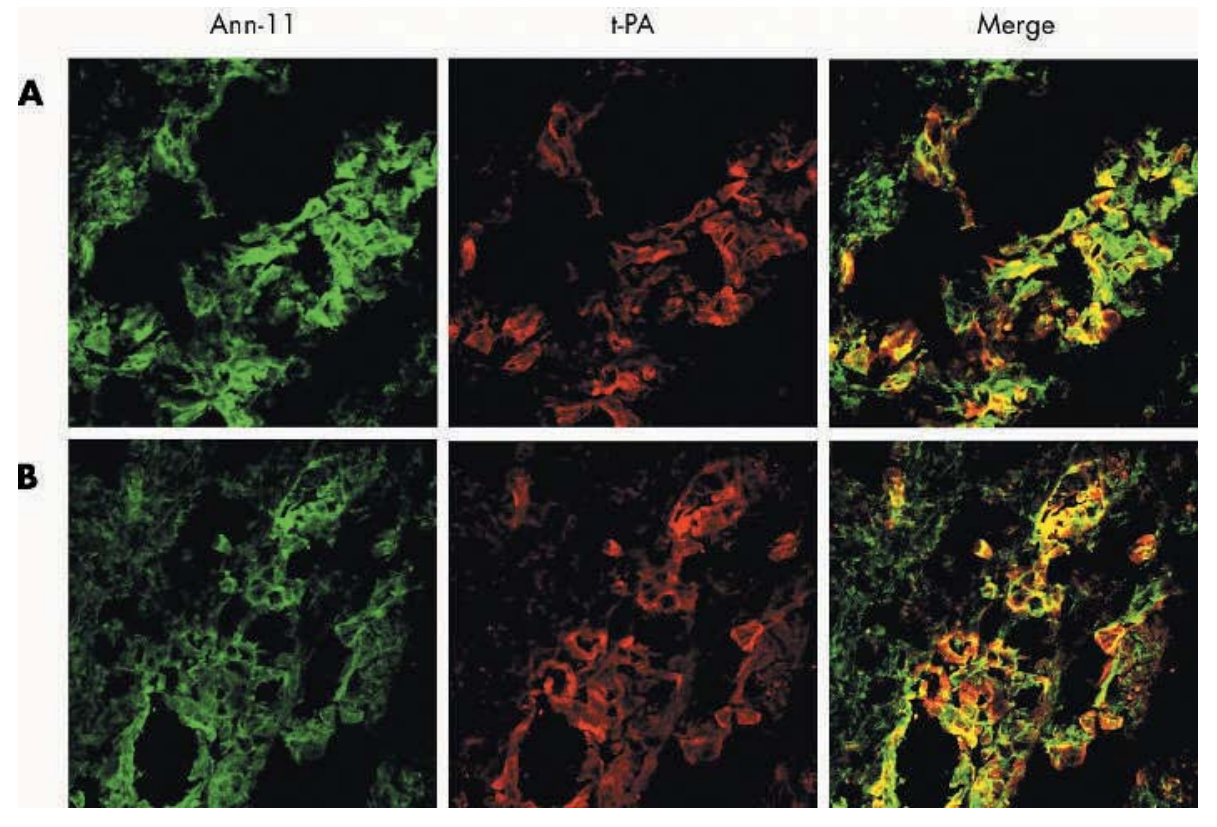

Figure 5 Immunocolocalisation of tissue-type plasminogen activator (t-PA) and annexin II in pancreatic tumours. (A) and (B) show representative images of different tumour samples processed for double immunofluorescence staining with mouse antiannexin II and goat anti-t-PA antibodies. Immunostaining for annexin II (Ann-II) is shown in green, immunostaining for t-PA in red, and colocalisation is shown in yellow (Merge). Original magnification $\times 200$. 

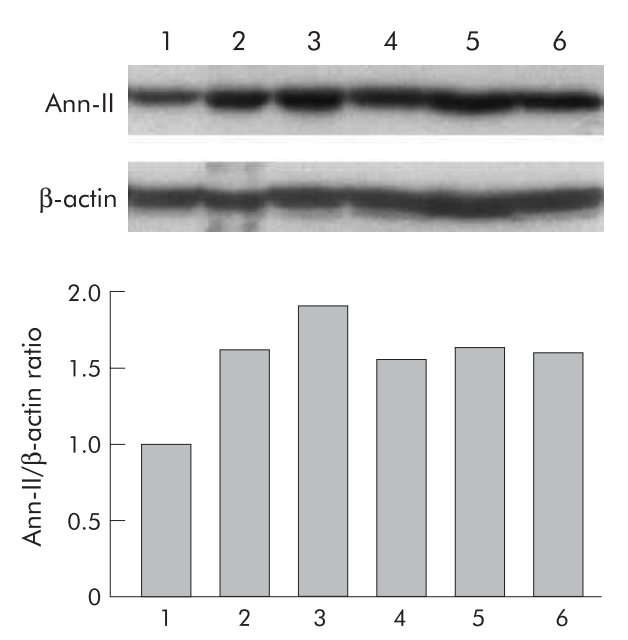

Figure 6 Expression of annexin II in pancreatic cancer cell lines. Western blotting with antiannexin II antibody of cellular protein extracts $(50 \mu \mathrm{g})$ from the cell lines: lane 1, SK-PC-1; lane 2, CAPAN-1; lane 3, RWP-1; lane 4, BxPC-3; lane 5, PANC-1; and lane 6, Hs766T. Blots were normalised by subsequent incubation with antibodies to $\beta$-actin. The histogram at the bottom shows the ratio of annexin II/ $\beta$-actin values obtained by laser scanning densitometry of autoradiograms.

rt-PA; at $75 \mathrm{M}$ excess of competitor t-PA, binding was reduced by $73.5 \%$ (fig $3 \mathrm{~A}$ ).

To discard the fact that the observed binding of t-PA involves interactions with acellular components, such as proteins of the extracellular matrix, cells in suspension were also assayed. Results from these experiments indicated saturable binding of t-PA to PANC-1 cells in suspension, with a $K_{D}$ of $34 \mathrm{nM}$, very similar to the results obtained previously (not shown). Thus pancreatic cancer cells express a surface protein capable of binding t-PA specifically and with high affinity while maintaining its activity, and thus may be the mediator of t-PA activities in these tumours. ${ }^{15}$

\section{t-PA interacts with annexin II on the surface of pancreatic cancer cells}

Because annexin II, the receptor for t-PA in endothelial cells, was previously determined to be overexpressed in pancreatic cancer, ${ }^{13} 3839$ we studied its contribution to the binding of t-PA to pancreatic cancer cells. Earlier work identified the sequence LCKLSL (residues 8-13) from the annexin II protein as the critical region involved in the interaction with t-PA. ${ }^{34}$ This peptide inhibited $95 \%$ of binding of t-PA to annexin II. ${ }^{34}$ As shown in fig 3B, binding of rt-PA to PANC-1 cells was significantly reduced to mean 60 (SEM 3)\% by peptide LCKLSL but no inhibition was observed with the control peptide LGKLSL (binding was 99 (4)\%), suggesting that annexin II may be involved in t-PA binding to pancreatic cells, and confirming that the Cys ${ }^{9}$ in annexin II is required for the interaction. ${ }^{34}$ To prove these results, cells were treated with EGTA to reduce the amount of annexin II from the cell surface. ${ }^{35}$ In the presence of EGTA, annexin II was recovered in the supernatant (fig 3C, inset) and binding of rt-PA to cells was reduced to 65.9 (4.4)\% (fig 3 C). However, when EGTA was added in combination with peptide LCKLSL, t-PA binding was further reduced to $36.8(2.4) \%$. These results support the notion that the interaction with annexin II accounts for most of the t-PA binding to pancreatic cell surfaces.

To confirm the interaction of t-PA with annexin II, we performed co-immunoprecipitation experiments using specific antibodies on SK-PC-1 cells that express high levels of
Table 1 Expression of tissue-type plasminogen activator (t-PA) and annexin II, and invasive capacity of pancreatic cancer cells

\begin{tabular}{lcll}
\hline Cell line & t-PA $^{*}$ & Annexin-IIt & Invasion $\ddagger$ \\
\hline SK-PC-1 & 20 & 1 & +++ \\
CAPAN-1 & 17.8 & 1.61 & ++ \\
RWP-1 & 5.1 & 1.9 & ++ \\
BxPC-3 & 0 & 1.54 & + \\
PANC-1 & 0 & 1.62 & + \\
Hs766T & 0 & 1.58 & + \\
\hline
\end{tabular}

*Expression of t-PA, as determined by ELISA assays.

†Expression of annexin II determined by western blotting was normalised to expression of $\beta$-actin.

$\ddagger$ The invasive capacity of cells in vitro was determined and quantified as described in experimental procedures.

both proteins. Isotype matched antibodies to annexin I were used as a control. Immunoprecipitations with antiannexin II antibody followed by western blotting analyses with antit-PA antibody revealed the presence of t-PA in immunoprecipitated proteins (fig 4). In contrast, no detectable t-PA was present in immunocomplexes formed by annexin I antibodies. Conversely, when cell extracts were immunoprecipitated with anti-t-PA antibody, annexin II was coimmunoprecipitated. However, not all t-PA secreted by SKPC-I cells co-immunoprecipitated with annexin II, and vice versa, suggesting that they may correspond to molecular forms that do not interact with each other.

\section{t-PA and annexin II colocalise at the surface of human pancreatic tumours}

To determine whether the interaction of t-PA and annexin II is present in vivo, we analysed the distribution pattern of annexin II and t-PA in human tumour tissue sections by double immunofluorescent staining and confocal microscopy. As shown in fig 5, both proteins were expressed at high levels in epithelial cancer cells and colocalisation was detected at membrane sites. t-PA and annexin II were also found at independent locations, in agreement with our previous results.

\section{Annexin II and t-PA overexpression correlate with invasion in pancreatic cancer cells}

Annexin II overexpression in pancreatic, colon, and gastric cancer cells correlates with a poor prognosis. ${ }^{138-42}$ We studied expression of annexin II in several pancreatic cancer cell lines by western blotting and the invasion abilities of these cells in vitro, on Matrigel coated filters. As shown in fig 6, levels of annexin II were similar in all cell lines, despite differences in their ability to invade ${ }^{15}$ (table 1 ). Data summarised in table 1 show that levels of expression of t-PA, but not those of annexin II, directly relate to a higher capacity for invasion.

\section{t-PA/annexin II interaction is critical for the invasive capacity of cancer cells in vitro}

We analysed whether the interaction of t-PA with annexin II is required for cells to invade, through Matrigel in vitro. Figure 7 shows that SK-PC-1 cells efficiently invade Matrigel. However, in the presence of the blocking hexapeptide LCKLSL, cell invasion was significantly reduced to mean 62 (SEM 11)\% of control cells at 72 hours. Invasion was also markedly inhibited by the use of this peptide at 24 and 48 hours. Invasion in the presence of a control peptide was no different from untreated cells, suggesting that the interaction of t-PA with annexin II is important for the pancreatic cell invasion process. 
LCKLSL

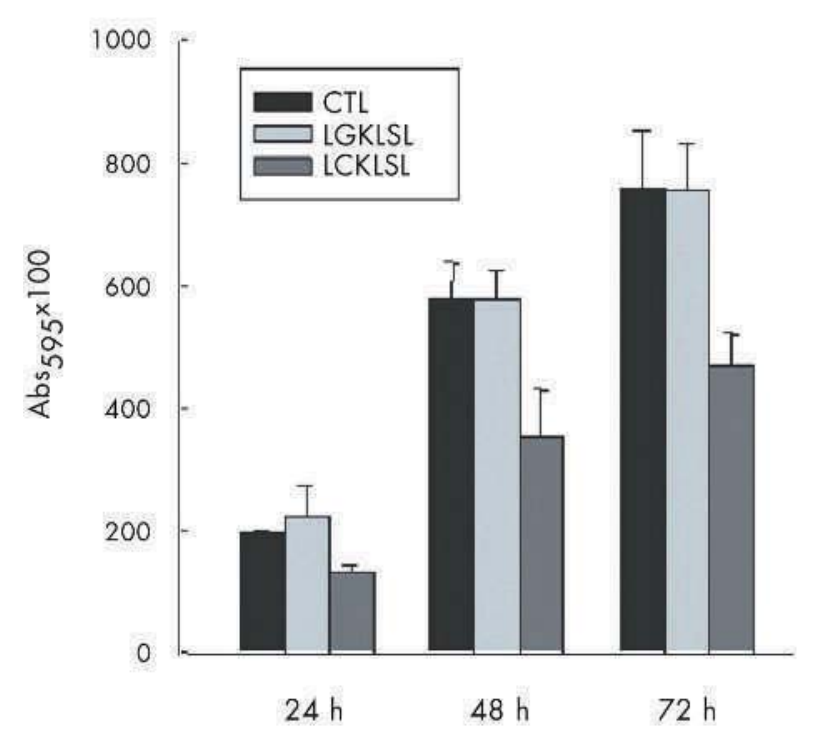

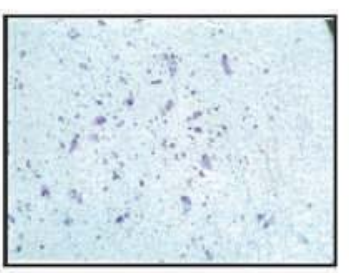
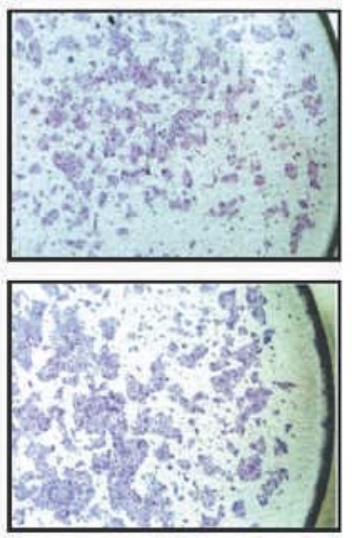

LGKLSL

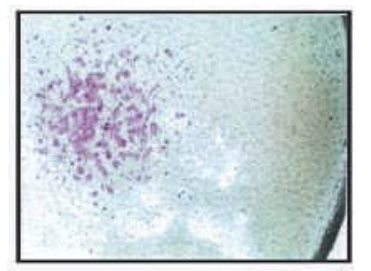

$24 \mathrm{~h}$

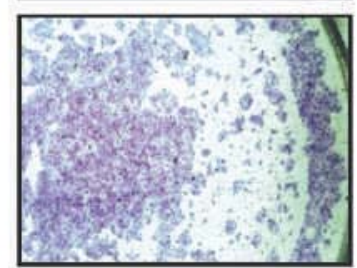

$48 \mathrm{~h}$

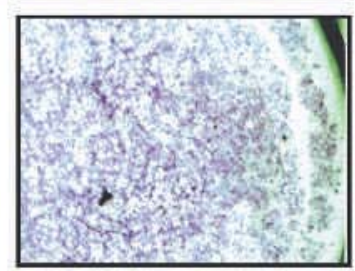

Figure 7 Role of the interaction of tissue-type plasminogen activator (t-PA) with annexin II in invasion. SK-PC-1 cells were cultured on Matrigel coated Transwell filters for 24,48 , and 72 hours, with or without the peptide LCKLSL $(5 \mathrm{mM})$ or the control peptide LGKLSL $(5 \mathrm{mM})$ added to the upper chamber. Left panel, quantitative determination of invading cells representing the mean (SEM) of two experiments performed in triplicate. Inhibition of invasion by peptide LCKLSL was significant at 72 hours ( $p=0.084$ at 24 hours, $p=0.056$ at 48 hours, and $p=0.009$ at 72 hours). Right panel, cells at the bottom surface of Transwell membranes stained with crystal violet in a representative experiment.

\section{DISCUSSION}

We have previously shown that t-PA, highly expressed in the majority of pancreatic tumours and cell lines but not in normal pancreatic tissue, is required for the invasion, proliferation, and angiogenesis of these tumours. ${ }^{12} 1315 \mathrm{We}$ have also shown that annexin II is overexpressed in pancreatic adenocarcinomas and localises at the basolateral compartment of SK-PC- 1 cells. ${ }^{13}$ Localisation of active t-PA at the cell surface permits local activation of plasmin, imparts proteolytic and invasive advantages to tumour cells, and is also essential for t-PA dependent activation of signal transduction. ${ }^{15}$ However, so far the identities of the specific cell surface binding molecules for t-PA in pancreatic cancer cells have not been elucidated.

In the present study, we demonstrated the presence of high affinity binding sites on cell membranes that maintain t-PA as an active enzyme and contribute to the invasive properties of SK-PC-1 cancer cells. By measuring only active t-PA bound to extracellular membranes of cells, we have detected specific and saturable binding for t-PA in SK-PC-1 and PANC-1 cells. This binding was significantly inhibited by a specific peptide corresponding to the $\mathrm{N}$ terminus of the annexin II protein (residues 8-13), and also by treatment with EGTA that removes most of annexin II from the cell surface, suggesting that annexin II is a binding site for t-PA. In addition, the interaction was demonstrated by co-immunoprecipitation in cell extracts in vitro and co-immunolocalisation in tumours. Finally, the significance of the interaction was functionally demonstrated by inhibition of invasion detected in the presence of the blocking hexapeptide. Based on these data, we conclude that annexin II is a t-PA binding site on the surface of pancreatic cancer cells and that this interaction is important for the invasive capacity of cells.

In HUVEC cells, treatments with EGTA, antisense oligonucleotides to annexin II, or antiannexin II antibodies results in a reduction in specific binding of t-PA to $40-50 \%$ of controls, values comparable with our results in pancreatic cells obtained with EGTA or the peptide LCKLSL. $^{34}{ }^{37}$ Interestingly, the inhibitory effect on t-PA binding to pancreatic cancer cells after treatment with EGTA combined with the peptide LCKLSL was higher than inhibition from individual treatments. These results may be explained by the following: (i) annexin II may be present on surface membranes as monomers or heterotetramers with $\mathrm{pl}^{1723}$; (ii) in HUVEC cells, a portion of annexin II, likely the heterotetrameric annexin II/pll, binds to membranes in a $\mathrm{Ca}^{2+}$ independent way and is thus resistant to EGTA treatment ${ }^{23} 43$; and (iii) the activity of t-PA is increased when it is bound to the heterotetrameric annexin II with respect to monomeric annexin II. ${ }^{23}$ Thus in our cells the efficacy of EGTA treatment on t-PA binding to annexin II may be partially occulted by the increased activity of t-PA bound to the tetrameric annexin II. In summary, inhibition of the interaction obtained by EGTA and the inhibitory peptide is significant, consistent with annexin II being a major binding site for t-PA on the surface of pancreatic tumour cells.

None the less, in polarised SK-PC-1 cells, t-PA is also bound to external apical membranes not containing annexin II (VD and RP, unpublished observations), suggesting that an additional protein(s) may function as a binding site for t-PA in these cells. In vascular smooth muscle cells, a high affinity binding site different from annexin II that maintains the protease active and shows a $\mathrm{K}_{\mathrm{D}}(25 \mathrm{nM})$ very similar to that described here ${ }^{30}$ has recently been identified as the transmembrane protein CKAP4..$^{32}$ Amphoterin, that binds t-PA in the central nervous system and is implicated in invasion, ${ }^{26} 44$ is also expressed by SK-PC-1 cells at high levels (VD and RP, unpublished observations). However, the non-saturable binding kinetics of t-PA to this site ${ }^{26}$ suggest that it is not the binding site detected in our experiments. Cytokeratin 8 
also binds t-PA in a specific and saturable manner in breast cancer cells $\mathrm{s}^{45}$ and promotes cell surface plasmin generation, but the reported $K_{D}(250(48) n M)$ is significantly different from that determined in our experiments. ${ }^{21}$ These observations suggest that pancreatic tumour cells may have more than one membrane molecule, with similar binding affinities for t-PA, possibly to focus plasmin generation at different membrane sites, the relevance of which in the process of tumour progression must be investigated.

Amphoterin, cytokeratin 8, and annexin II are cytosolic proteins lacking a signal sequence, and yet extracellular functions for these proteins have been described. In this regard, annexin II has been found in exosomes, an unconventional secretion pathway for proteins lacking a signal sequence. ${ }^{46}$

Our co-immunoprecipitation experiments clearly demonstrated the interaction of t-PA with annexin II. However, only a fraction of the two proteins interact with each other, likely corresponding to the fractions localised at the surface compartment of cells. The partial co-immunolocalisation of both proteins in vivo supports this notion, showing both t-PA and annexin II overexpression in tumours and colocalisation at particular membrane sites.

The LCKLSL peptide inhibits t-PA binding to cells and invasion through Matrigel at comparable levels, confirming that the active t-PA bound to surface annexin II is needed for invasion. SK-PC-1 and PANC-1 cells also express high levels of $\mathrm{u}-\mathrm{PA}$ and $\mathrm{u}-\mathrm{PAR}$ that contribute to the invasion process. ${ }^{13} 1547$ Thus inhibition of invasion obtained by the disruption of annexin II/t-PA interaction in the experiments shown here may account for most of the t-PA dependent invasive capacity.

Our results are the first to show the specific interaction of t-PA with annexin II on pancreatic cancer cell surfaces and its relevance for the invasive process. Understanding the precise mode of interaction of t-PA with pancreatic cancer cells and the molecular mechanisms used for invasion will help in the understanding of the contribution of this protease to cancer progression and in the development of more effective therapeutic strategies in the future.

\section{ACKNOWLEDGEMENTS}

The authors are grateful to F Picatoste and J Sáez for useful discussions and suggestions. This work was supported by the Ministerio de Ciencia y Tecnología (SAF2000-0195, SAF2001-1969) and Marató-TV3 (1999). VMD was a recipient of a Beca de Formación del Personal Investigador (Ministerio de Ciencia y Tecnología). MH was a recipient of a pre-doctoral fellowship from the Marató-TV3, and from the Institut de Recerca Vall d'Hebrón.

\section{Authors' affiliations}

V M Díaz ${ }^{*}$ Unitat de Recerca Biomèdica, Hospital Materno-Infantil, Hospitals Vall d'Hebrón, Pg Vall d'Hebrón 1 19-129, 08035 Barcelona, Spain, and Institut de Biologia Molecular de Barcelona, Consejo Superior de Investigaciones Científicas, c Jordi Girona, 18-26, 08034, Barcelona, Spain

M Hurtado, J Reventós, R Paciucci, Unitat de Recerca Biomèdica, Hospital Materno-Infantil, Hospitals Vall d'Hebrón, Pg Vall d'Hebrón 119-129, 08035 Barcelona, Spain

T M Thomson, Institut de Biologia Molecular de Barcelona, Consejo Superior de Investigaciones Científicas, c Jordi Girona, 18-26, 08034, Barcelona, Spain

*Present address: Department of Molecular Biology and Functional Genomics, Università Vita Salute San Raffaele and DIBIT, via Olgettina 58, 20132 Milan, Italy

\section{REFERENCES}

1 Lijnen HR. Elements of the fibrinolytic system. Ann NY Acad Sci 2001;936:226-36.
2 Lijnen HR. Plasmin and matrix metalloproteinases in vascular remodeling Thromb Haemost 2001;86:324-33.

3 Pepper MS. Role of the matrix metalloproteinase and plasminogen activatorplasmin systems in angiogenesis. Arterioscler Thromb Vasc Biol 2001;21:1104-17.

4 Bell WR. The fibrinolytic system in neoplasia. Semin Thromb Hemost 1996;22:459-78.

5 Andreasen PA, Egelund R, Petersen $\mathrm{HH}$. The plasminogen activation system in tumor growth, invasion, and metastasis. Cell Mol Life Sci 2000;57:25-40.

6 Bizik J, Lizonova A, Stephens RW, et al. Plasminogen activation by t-PA on the surface of human melanoma cells in the presence of alpha 2-macroglobulin secretion. Cell Regul 1990;1:895-905.

7 Mimura K, Sueishi K, Yasunaga C, et al. Fibrinolysis activity promotes tumor invasiveness of B16 melanoma cell lines through a reconstituted gel matrix. Invasion Metastasis 1992;12:24-34.

8 Stack MS, Gray RD, Pizzo SV. Modulation of murine B16F10 melanoma plasminogen activator production by a synthetic peptide derived from the laminin A chain. Cancer Res 1993;53:1998-2004.

9 Neuman T, Stephens RW, Salonen EM, et al. Induction of morphological differentiation of human neuroblastoma cells is accompanied by induction of tissue-type plasminogen activator. J Neurosci Res 1989;23:274-81.

10 Sugiura $Y, M a L$, Sun $B$, et al. The plasminogen-plasminogen activator (PA) system in neuroblastoma: role of PA inhibitor-1 in metastasis. Cancer Res 1999;59:1327-36.

11 Menell JS, Cesarman GM, Jacovina AT, et al. Annexin II and bleeding in acute promyelocytic leukemia. N Engl J Med 1999;340:994-1004.

12 Paciucci R, Berrozpe G, Tora $M$, et al. Isolation of tissue-type plasminogen activator, cathepsin $\mathrm{H}$, and non-specific cross-reacting antigen from SK-PC-1 pancreas cancer cells using subtractive hybridization. FEBS Lett 1996;385:72-6.

13 Paciucci R, Tora M, Díaz VM, et al. The plasminogen activator system in pancreas cancer: role of t-PA in the invasive potential in vitro. Oncogene 1998; 16:625-33

14 Escaffit F, Estival A, Bertrand C, et al. FGF-2 isoforms of 18 and $22.5 \mathrm{kDa}$ differentially modulate t-PA and PAl-1 expressions on the pancreatic carcinoma cells AR4-2J: consequences on cell spreading and invasion, Int J Cancer 2000;85:555-62.

15 Díaz VM, Planagumà J, Thomson TM, et al. Tissue plasminogen activator is required for the growth, invasion, and angiogenesis of pancreatic tumor cells. Gastroenterology 2002; 122:806-19.

16 Haijar KA. Cellular receptors in the regulation of plasmin generation. Thromb Haemost 1995:74:294-301.

17 Brownstein C, Falcone DJ, Jacovina A, et al. A mediator of cell surfacespecific plasmin generation. Ann N Y Acad Sci 2001;947:143-55.

18 Miles LA, Dahlberg CM, Plescia J, et al. Role of cell-surface lysines in plasminogen binding to cells: identification of alpha-enolase as a candidate plasminogen receptor. Biochemistry 1991;30:1682-91.

19 Redlitz A, Fowler BJ, Plow EF, et al. The role of an enolase-related molecule in plasminogen binding to cells. Eur J Biochem 1995;227:407-15.

20 Correc $\mathrm{P}$, Fondaneche MC, Bracke $M$, et al. The presence of plasmin receptors on three mammary carcinoma MCF-7 sublines. Int J Cancer 1990;46:745-50

21 Hembrough TA, Li L, Gonias SL. Cell-surface cytokeratin 8 is the major plasminogen receptor on breast cancer cells and is required for the accelerated activation of cell-associated plasminogen by tissue-type plasminogen activator. J Biol Chem 1996;271:25684-91.

22 Cesarman GM, Guevara CA, Haijar KA. An endothelial cell receptor for plasminogen/tissue plasminogen activator (t-PA). II. Annexin II-mediated enhancement of t-PA-dependent plasminogen activation. J Biol Chem 1994;269:21198-203.

23 Kassam G, Choi KS, Ghuman J, et al. The role of annexin II tetramer in the activation of plasminogen. J Biol Chem 1998;273:4790-9.

24 Siao CJ, Tsirka SE. Tissue plasminogen activator mediates microglial activation via its finger domain through annexin II. J Neuroscience 2002;22:3352-8.

25 Jacovina AT, Zhong F, Khazanova E, et al. Neuritogenesis and the nerve growth factor-induced differentiation of PC-12 cells requires annexin IImediated plasmin generation. J Biol Chem 2001;276:49350-8.

26 Parkkinen J, Rauvala $\mathrm{H}$. Interactions of plasminogen and tissue plasminogen activator (t-PA) with amphoterin. Enhancement of t-PA-catalyzed plasminogen activation by amphoterin. J Biol Chem 1991;266:16730-5

27 Gonias SL, Hembrough TA, Sankovic M. Cytokeratin 8 functions as a major plasminogen receptor in select epithelial and carcinoma cells. Front Biosci 2001;6:D1403-11.

28 Bizik J, Stephens RW, Grofova M, et al. Binding of tissue-type plasminogen activator to human melanoma cells. J Cell Biochem 1993;51:326-35.

29 Bizik J, Trancikova D, Felnerova D, et al. Spatial orientation of tissue-type plasminogen activator bound at the melanoma cell surface. Biochem Biophys Res Commun 1997;239:322-8.

30 Ellis V, Whawell SA. Vascular smooth muscle cells potentiate plasmin generation by both urokinase and tissue plasminogen activator-dependent mechanisms: evidence for a specific tissue-type plasminogen activator receptor on these cells. Blood 1997;90:2312-22.

31 Werner F, Razzaq TM, Ellis V. Tissue plasminogen activator binds to human vascular smooth muscle cells by a novel mechanism. Evidence for a reciprocal linkage between inhibition of catalytic activity and cellular binding. J Biol Chem 1999;274:21555-61

32 Razzaq TM, Bass R, Vines DJ, et al. Functional regulation of tissue plasminogen activator on the surface of vascular smooth muscle cells by the type-ll transmembrane protein p63 (CKAP4). J Biol Chem 2003;278:42679-85. 
33 Ranby $M$, Norrman B, Wallen P. A sensitive assay for tissue plasminogen activator. Thromb Res 1982;27:743-9.

34 Hajiar KA, Mauri L, Jacovina AT, et al. Tissue plasminogen activator binding to the annexin II tail domain. Direct modulation by homocysteine. J Biol Chem 1998:273:9987-93.

35 Falcone DJ, Borth W, Khan KM, et al. Plasminogen-mediated matrix invasion and degradation by macrophages is dependent on surface expression of annexin II. Blood 2001; 97:777-84.

36 Thiel C, Osborn M, Gerke V. The tight association of the tyrosine kinase substrate annexin II with the submembranous cytoskeleton depends on intact p1 1- and $\mathrm{Ca}(2+)$-binding sites. J Cell Sci 1992;103:733-42.

37 Haijar KA, Jacovina AT, Chacko J. An endothelial cell receptor for plasminogen/tissue plasminogen activator. I. Identity with annexin II. J Biol Chem 1994:269:21191-7.

38 Vishwanatha JK, Chiang Y, Kumble KD, et al. Enhanced expression of annexin II in human pancreatic carcinoma cells and primary pancreatic cancers. Carcinogenesis 1993;14:2575-9.

39 Kumble KD, Hirota M, Pour PM, et al. Enhanced levels of annexins in pancreatic carcinoma cells of Syrian hamsters and their intrapancreatic allografts. Cancer Res 1992;52:163-7.

40 Emoto K, Yamada Y, Sawada H, et al. Annexin II overexpression correlates with stromal tenascin-C overexpression: a prognostic marker in colorectal carcinoma. Cancer 2001:92:1419-26.
41 Emoto K, Sawada H, Yamada Y, et al. Annexin II overexpression is correlated with poor prognosis in human gastric carcinoma. Anticancer Res 2001;21:1339-45.

42 Mai J, Waisman DM, Sloane BF. Cell surface complex of cathepsin B/annexin II tetramer in malignant progression. Biochim Biophys Acta 2000;1477:215-30.

43 Jost M, Zeuschner D, Seemann J, et al. Identification and characterization of a novel type of annexin-membrane interaction: $\mathrm{Ca} 2+$ is not required for the association of annexin II with early endosomes. J Cell Sci 1997;1 10:221-8.

44 Tiberio A, Farina AR, Tacconelli A, et al. Retinoic acid-enhanced invasion through reconstituted basement membrane by human SK-N-SH neuroblastoma cells involves membrane-associated tissue-type plasminogen activator. Int J Cancer 1997;73:740-8.

45 Kralovich KR, Li L, Hembrough TA, et al. Characterization of the binding sites for plasminogen and tissue-type plasminogen activator in cytokeratin 8 and cytokeratin 18. J Protein Chem 1998;17:845-54

46 Thery C, Boussac M, Veron P, et al. Proteomic analysis of dendritic cellderived exosomes: a secreted subcellular compartment distinct from apoptotic vesicles. J Immunol 2001;166:7309-18.

47 Paciucci R, Vila MR, Adell T, et al. Activation of the urokinase plasminogen activator/urokinase plasminogen activator receptor system and redistribution of E-cadherin are associated with hepatocyte growth factor-induced motility of pancreas tumor cells overexpressing Met. Am J Pathol 1998;153:201-12.

\section{EDITOR'S QUIZ: GI SNAPSHOT}

\section{An unusual treatment for a colonic polyp}

\section{Clinical presentation}

A 42 year old woman, gravida 3 para 2, was referred to our outpatient clinic for abdominal pain, bloody diarrhoea, and sideropenic anaemia (haemoglobin $9.9 \mathrm{~g} / \mathrm{dl}$, iron $40 \mu \mathrm{g} / \mathrm{dl}$; ferritin $3 \mathrm{ng} / \mathrm{dl}$ ). Eight months earlier she had underwent colonoscopy. A polyp in the sigmoid colon had been found and removed by hot snare polypectomy. Histological examination had showed the presence of endometriotic foci. After polypectomy, symptoms disappeared. She had never complained of dysmenorrhoea or dyspareunia, symptoms often associated with endometriosis.

Six months later symptoms recurred. We performed colonoscopy twice, during menses and in the intermenstrual period (figs 1, 2, respectively). Colonoscopies showed a polypoid lesion at the same site of the previous polypectomy.

\section{Question}

What do these endoscopic images suggest and how would you manage this patient?

See page 1019 for answer

This case is submitted by:

A Viscido, A Aratari, M Pimpo, V D'Ovidio, G Frieri, R Caprilli GI Unit, Department of Clinical Sciences and Gynaecological Unit, University "La Sapienza", Rome, Italy M G Porpora, M Crobu Department of Gynaecological Sciences, Perinatology and Child Health, University "La Sapienza", Rome, Italy

Correspondence to: A Aratari, Dipartimento di Scienze Cliniche, Policlinico Umberto I, Viale del Policlinico 155, 00161 Roma, Italy; aalisa@tin.it doi: $10.1136 /$ gut.2003.026963

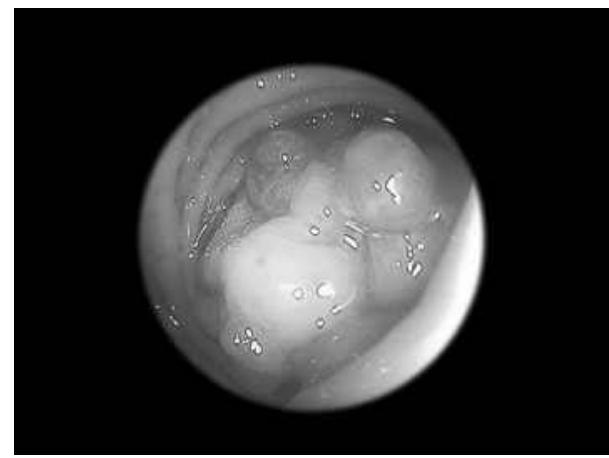

Figure 1

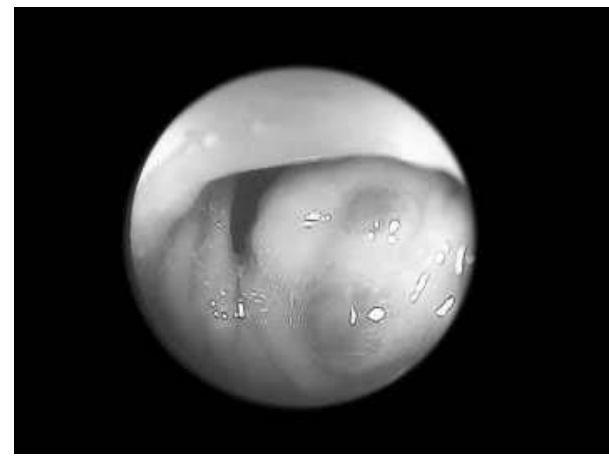

Figure 2 